\title{
La inserción de Latinoamérica en el mundo globalizado Alicia Poderti *
}

\begin{abstract}
Resumen / La inserción de Latinoamérica en el mundo globalizado
A partir de una frase del historiador inglés Eric Hobsbawm se ingresa a un texto polifónico en el que se intenta pensar qué pasa con Latinoamérica en el contexto de la globalización. Esa es tal vez una de las mayores dudas que la autora intenta responder desde diferentes perspectivas en este ensayo. Si lugar a dudas, un tema complejo, un territorio difícil de precisar desde una perspectiva simple y que necesita de una respuesta compleja que atienda a una gran cantidad de aspectos. Por este motivo se analiza la idea de nación desde diferentes perspectivas, la construcción de bloques regionales, las tecnologías de la decisión, cuál es el papel de los investigadores y cómo los habitantes de América Latina son inmigrantes portadores de una compleja identidad.
\end{abstract}

\section{Palabras clave}

Globalización - historia de las ideas - identidad - Latinoamérica.

\section{Summary / Latin American insertion in the globalised world}

After a statement by the English historian Eric Hobsbawm the author proposes a text in which she tries to reflect about what happens with Latin America in the context of the globalization. That is perhaps one of the majors doubts that the author tries to respond from different perspective in this essay. She approaches a complex subject, hard to precise from a simple perspective and that needs a complex answer that takes care of a great amount of aspects. For this reason the nation idea from different perspectives, the construction of regional blocks, the technologies of the decision, the role of investigators and how the inhabitants of Latin America are carrying immigrants of a complex identity .

\section{Key words}

Globalisation - history of ideas - identity - Latin America.

\section{Resumo / A inserção de Latinoamerica no mundo globalizado}

A partir duma frase do historiador inglês Eric Hobsbawm se ingressa a um texto polifónico no que se tenta pensar qué acontece com Latinoamérica no contexto da globalização. Essa é talvez uma das maiores dúvidas do que a autora tenta responder desde diferentes perspectivas neste ensaio. Sem lugar a Dúvidas, um texto complexo, um território difícil de precisao desde uma perspectiva simples e que precisa de uma resposta complexa que atenda a uma grande quantidade de aspectos. Por isso analissa-se a idéia de nação desde diferentes perspectivas, a construção de blocos regionais as tecnologias da decisão, qual é o rol dos pesquiçadores e cómo os habitantes de América Latina são imigrantes portadores de uma complexa identidade.

\section{Palavras clave}

Globalização - história das idéias - identidade - Latinoamérica.

\footnotetext{
* Doctora de la Univesidad Nacional de Cuyo. Especializada en temas transdisciplinarios, Investigadora de carrera del CONICET (Consejo Nacional de Investigaciones Científicas y Técnicas, Argentina). Actualmente se desempeña como Investigadora de carrera del CONICET (Consejo Nacional de Investigaciones Científicas Doctorada en la Universidad Nacional de Cuyo. Postdoctorado en Historia Iberoamericana (España y Técnicas, Presidencia de la Nación, Argentina). Es Profesora de diferentes carreras de Posgrado en universidades argentinas (Universidad de La Plata, Universidad Nacional de Cuyo, Universidad Nacional de Salta, Universidad Nacional de Jujuy) y universidades extranjeras (Universidad de Gotemburgo Suecia; Universidad de New South Wales, Australia; Universidad de Huelva, España; Universidad Pedagógica de Bogotá, entre otras).
} 
Se ha cerrado el telón sobre una centuria. El historiador Eric Hobsbawm ha publicado su Historia del siglo XX (1998), un estudio de las transformaciones y los derrumbamientos en el orden político, económico, social, científico y cultural. Allí, el autor admite que no intenta trazar predicciones sobre un paisaje que ahora ha quedado irreconocible, luego de los movimientos tectónicos que se han producido en aquellos cien años. El título original del libro de Hobsbawm -Extremos. El breve siglo XX (Extremes. The short twentieth century)- condensa la idea medular de su planteo historiográfico, ya que confronta este trayecto con el extenso período anterior. Mientras el largo siglo XIX culminaba con la caída de la civilización occidental, el veloz transcurso comprendido entre 1914 y 1991 desemboca en el reacomodo de los lugares de autoridad a nivel global y los apuros de la democracia en diversos países del planeta.

Recordemos que, hacia finales del siglo XX, la generación del capitalismo impreso -gestora de las conciencias nacionalesentra en crisis. En el nivel político y económico se desarrolla una plataforma ideológica desde la cual se legaliza el derecho a injerencia de ciertas grandes potencias, ahora llamadas estructurantes, y que conforman la teoría y práctica del pretendido imperialismo bueno. En el plano simbólico y cultural, los malestares se traducen en la aparición de nuevas formas de conciencia e interpretación de la realidad, lecturas del mundo que desnudan el fetiche tecnológico, el Estado omnímodo, la burbuja financiera y la construcción de nuevos instrumentos de poder.

El proceso de globalización o transnacionalización capitalista integra un estilo de civilización que modeliza un mundo unificado, inseparable histórica y geográficamente desde los tiempos de la Colonia y que, sin embargo, está fragmentado por profundas divisiones económicas, sociales, étnicas y culturales.

La uniformidad avasallante del neocolonialismo se expandió a través de la tendencia histórica de la globalización. Pero en el último proceso de globalización no se invadieron los territorios -como ocurrió en el período colonial-, sino que los mercados son han sido los cautivos. El correlato de las mutaciones económico-políticas, operando en la metamorfosis de las identidades institucionales y la pugna por entrar al convite de segunda categoría reservado para las naciones pobres, puede leerse también en el registro simbólico y cultural.

El proceso de globalización implica la extensión al resto del mundo del patrón cultural dominante. Esa pauta tiene un desarrollo unilateral, con una creciente sofisticación de medios tecnológicos y una abrumadora implosión comunicacional. En estos nuevos espacios multiculturales, crece la distancia planteada entre el universalismo y la globalización. Mientras en la última, hay sectores enormes de la cultura humana que están ausentes, el universalismo constituiría aquel ese estadio cultural deseable en el que aporten todas o al menos la mayoría de las culturas -aún las marginales-.

La segunda mitad del siglo plantea la reestructuración de las identidades locales, nacionales y globales, como consecuencia de los grandes cambios políticos y económicos a nivel mundial. Se produce el pasaje de las identidades modernas hacia las posmodernas. Como ha estudiado Néstor García Canclini (1996), las identidades modernas -territoriales y casi siempre monolingüísticas-, se habían fijado tras la subordinación de las regiones y etnias dentro de un espacio arbitrariamente definido. Este espacio, Ilamado "nación", se oponía -desde la forma que le daba su organización estatal- a otras naciones. En cambio, las identidades posmodernas son transterritoriales y multilingüísticas. Operan mediante la producción industrial de cultura, ayudadas por la comunicación tecnológica y el consumo diferido y segmentado de los bienes. Estas identidades desdeñan las modalidades orales y escritas que cubrían espacios personalizados y se efectuaban a través de interacciones próximas. Así, las formas identitarias posmodernas no se estructuran desde la lógica de los estados sino desde la de los mercados.

Como hemos observado, las naciones desarrolladas concentran su poder creando polarización, asimetría y una acumulación ilimitada del capital y la tecnología. Este nuevo orden mundial produce una creciente ingobernabilidad de las periferias, cuyas masas están siempre oprimidas por el peso del fracaso económico de sus propios gobiernos. Unido al proceso de internacionalización del capital, del trabajo y del medio ambiente, se requiere como requisito indispensable realizar una privatización del estado (Cfr. Varese, 1997).

El pasaje de lo nacional a lo global y de lo público a lo privado provoca cambios en los modos de integración regional. El planetarismo define su núcleo en los medios de comunicación y en la conquista de espacio cibernético. Si recalamos en los estudios de la post-modernidad generados desde mediados de los años '80, analistas como Fredric Jameson, señalan la creciente expansión de la globalización como una consecuencia lógica del capitalismo tardío. Recordemos que Eric Hobsbawm utiliza con menor frecuencia el término "globalización" y prefiere hablar del "triunfo del capitalismo".

Como ya hemos referido, en el umbral del siglo XXI la reestructuración de los sistemas económicos tejen nuevas instancias en las configuraciones político-culturales de los países del globo. Los grandes conglomerados tienen una funcionalidad específicamente comercial e industrial. Pero en la base de este marco de trasnacionalización capitalista se plantea el ordenamiento de las economías en el mundo según las regulaciones impuestas por los bloques líderes.

Con cierta nostalgia hacia la etapa eurocéntrica, Hobsbawm veía en la Unión Europea un modelo que permitía delegar competencias supranacionales, nacionales, subnacionales y globales. Sin embargo, el historiador reconoce que la Unión Europea es un caso único, probablemente irrepetible. Pero desde principios de los '70, a medida que aumenta el abismo entre los países ricos y los pobres, el Banco Mundial y el Fondo Monetario Internacional, con el respaldo político de los Estados Unidos, han ido diseñando las políticas del libre mercado, de la empresa privada y del comercio mundial.

\section{Estrategias: la construcción de bloques regionales en Latinoamérica}

Como expresa Giddens, "la globalización económica es una realidad y mientras gran parte del comercio continúa "regionalizado", existe una economía plenamente global, a nivel de mercados financieros" (Giddens, 2000': 43)

En el interior del enorme país que se abre a los capitales del mundo, la aplicación del molde globalizante trae como consecuencia el previsto incremento de la desocupación, la marginación y el arrinconamiento social. Ante la uniformidad avasallante de estos poderosos gestos de neocolonialismo cultural, económico y político, la defensa de los regionalismos parece ser la única vía para insertarse satisfactoriamente en el mundo globalizado.

Para lograr equilibrio en las relaciones internacionales y evitar las consecuencias locales del nuevo orden mundial, como la exclusión y la pobreza, se impone la aparición de bloques regionales que, de hecho, ya estarían "creados" y necesitan 
un impulso político para funcionar coordinadamente. Así, las áreas que presentan características similares en su génesis geo-cultural debieran aglutinarse, reconociendo sus aspectos comunes en la estructura política y económica, en la dinámica migratoria y en su conformación lingüística.

Recordemos que la designación "América Latina" aparece en la segunda mitad del siglo XIX. Coherente con las filosofías de la latinidad que circulaban en la época, el nombre se configura en los discursos de identidad de la producción periodística, política y literaria. Los primeros en emplear el apelativo fueron Francisco Bilbao y José María Torres Caicedo, en un intento de dar cobertura ideológica al proyecto político de personalización de las dos formas del americanismo de entonces: la de los hispanoamericanos y la de los EE. UU.

Bilbao comienza a utilizar el gentilicio "latinoamericano" en una conferencia titulada "Iniciativa de la América", brindada en París, el 24 de junio de 1856. El mismo año, Torres Caicedo escribe en Las dos Américas: La raza de América latina/ al frente tiene la sajona raza. En 1879 este intelectual funda en París la Sociedad de la Unión Latinoamericana.

En el caso de Francisco Bilbao, el concepto se acuña desde un pensamiento anticolonialista y anti-imperialista, como parte de un proyecto de sociedad socialista. La "América" del pensamiento de Bilbao se compone de tres partes: la América latina, la sajona y la indígena. Así, el pensamiento de Bilbao se yergue como preanuncio de La raza cósmica de Vasconcelos, por cuanto sostiene que la combinación del genio sajón con el genio latino permitirá formar la síntesis de la civilización americana, destinada a regenerar el Viejo Mundo y a cumplir sobre la tierra los destinos del hombre soberano.

Yendo más atrás en el tiempo, recordemos los proyectos continentales de San Martín y Bolívar. Para Güemes, estratega del plan sanmartiniano, el ideal patriótico estaba concebido como un plan geo-político integral. Este diseño se articulaba a un proceso que convocaba a los distintos sectores sociales con el fin de realizar el proyecto de una libertad común para los países sudamericanos. Así, Güemes hizo de la causa de la Independencia la empresa de las masas movilizadas, enfrentando a los godos, a los porteños y a la oligarquía provincial. Cuando desaparece físicamente también se esfuma ese objetivo primordial y el pueblo queda desprotegido, sin líderes capaces de vehiculizar los sentimientos de las clases desfavorecidas. El triunfo del puerto cercena la posibilidad de un trazado económico y político regional que respondiera al programa continental. Se suceden las virulentas guerras entre federales y unitarios, con su fase condenatoria hacia muchos de los ideólogos de la emancipación (Poderti, 1999).

También conviene recordar que Juan Domingo Perón había impulsado en 1948 un proyecto que contó con la adhesión de casi todos los países del cono sur. Fracasado éste, se creó la Asociación Latinoamericana de Libre Comercio (ALALC). Este proyecto se insertaba dentro de una propuesta de integración continental de Latinoamérica en la que una política de unificación podía hacer frente a posibles intentos de invasión pacífica o violenta especialmente de los Estados Unidos, con el fin de apropiación de las reservas de comida y materia prima. Estas ideas supranacionales que impregnan el ideario peronista se asocian con su noción de continentalismo, basada en las ideas continentalistas de San Martín y Bolívar, una etapa en la evolución de la historia que reorganiza y supera a las naciones reuniéndolas por continentes. La siguiente etapa sería el universalismo o universalización, que es el estadio deseado por Perón y que, erróneamente, muchos quieren equiparar, desde la contemporaneidad, al fenómeno de la globalización. Ya el 25 de abril de 1945 Perón había pronunciado palabras claves en su ideario:

Norte, centro y sur del continente americano, vertebrados por la gigantesca mole andina, con la varia expresión de sus diversos pueblos, con la fuerza ancestral de sus profundas raíces autóctonas, templadas por el fuego civilizador de españoles, portugueses y anglosajones, bruñidas por las gestas emancipadoras de Washington, Bolívar y San Martín, y afirmadas por su rotunda voluntad soberana de naciones libres, pueden proclamar hoy en todas direcciones, porque ha florecido su rosa de los vientos, que, restablecida la paz, encontrarán, para defenderla, un baluarte en cada corazón americano. (Perón, 1997: 512).

Esta idea de aproximación espiritual entre países como Argentina, Uruguay, Paraguay, Bolivia, Chile, Brasil, Perú y Ecuador, impulsa la recíproca colaboración en el campo económico. En este sentido, Perón se adelanta a los tiempos y habla de una noción de "bloque" y de "personalidad continental". El 7 de noviembre de 1952 declara:

Nosotros hemos formado ya una entidad económica, una entidad política y una entidad social que se van consolidando. Nosotros tenemos resuelto el problema, y lo ideal sería llegar a unirnos con todos los demás pero en forma indestructible, no con unidad de discursos de cancillería, que poco unen. Han que unirse, y unirse con intereses. (Perón, 1997: 517-518).

Según los estudios contemporáneos, un conglomerado supranacional de gran incidencia en la conformación cultural del noroeste argentino es el que integra la región andina. En ella es posible detectar una zona de fuerte incidencia en la cultura incásica: Ecuador, Perú, Bolivia, norte de Chile y parte de Argentina. Crece entonces la necesidad de remontar aquellas configuraciones histórico-culturales e implementar planes estratégicos de re-ingeniería geopolítica a través de mecanismos de "empoderamiento" regional (Poderti, 2000).

\section{¿Y la categoría "Nación"?}

La constitución de los estados nacionales latinoamericanos que se efectúa a partir de la primera parte del siglo XIX respondía a las necesidades de los grupos dominantes -descendientes de los conquistadores y colonizadores europeos-, en el marco de la constitución y desarrollo de un mercado mundial. El proceso de constitución de nuevas comunidades históricas -las naciones- respondía en el Europa al proyecto e idea definidos en el pensamiento de la Revolución Francesa ("Nación una e indivisible"). Así, los ideólogos que organizaron la nacionalidad argentina importaron un modelo institucional exótico, un producto que se ajustara a los cronómetros occidentales y que, a la vez, defendiera algunas expresiones de la cultura autóctona.

Las leyes de la llustración que habían impulsado el proceso de emancipación condujeron la organización del estado nacional. En esta etapa comienza a requerirse de la literatura una función ancilar, al servicio del nuevo estado republicano para difundir los ideales de libertad, civilización y progreso como los pilares del proyecto de nación que se estaba gestando. Surge entonces una corriente de escritores comprometidos con la vida política del país y en cuya producción se generan 
imágenes que contribuyen a reforzar el proyecto de construcción de un imaginario nacional. La idea dinámica y de progreso evolutivo que caracteriza a la concepción de la historia para el romanticismo, el espíritu de la nacionalidad, la búsqueda de las raíces folklóricas nacionales y la determinación de aquello que se presenta como lo genuinamente propio de cada pueblo, signan la producción filosófica, sociológica y literaria del período. El falso mito del progreso que esperaba que América Latina alcanzara la prosperidad y el nivel cultural europeo si lograba vencer los impulsos de su barbarie, marca un cambio sustancial en la escritura literaria. El Romanticismo en Argentina colabora con el proyecto social de cambio, rechazando en sus textos cualquier influencia que entorpezca aquel plan.

Como ha expresado Benedict Anderson (1993), la nación moderna suele representarse a sí misma como una "comunidad imaginada", en la que los miembros de la comunidad nacional se imaginan -se les pide que se imaginen- vinculados por lazos horizontales y fraternales. Así, los caracteres de la nación "discreta, soberana y autónoma" se integran al "estilo de imaginar" propio de la nación moderna. En el proceso de constitución de las naciones se opera un proceso de "ficcionalización" fuertemente apoyado en la literatura. Así, la idea romántica de nación que surge en países como Argentina, se traduce como proyecto y realización de un proceso histórico conformado desde una ideología y también desde la ficción.

La novela y el periódico son las dos formas de imaginación que se generaron en el siglo XVIII y que proveyeron los medios técnicos necesarios para la representación de las comunidades imaginadas nacionales. Otras formas artísticas también han contribuido a la estructuración de las nacionalidades, como algunos poemas, canciones y, sobre todo, los himnos nacionales. Porque los himnos y canciones patrias simbolizan la idea de nación que se desea que los ciudadanos imaginen. (Cfr. Anderson, 1993: 200-217)

\section{Tecnologías de la decisión}

El proceso de constitución de nuevas comunidades históricas -las naciones- trajo como consecuencia que, en la lucha por la delimitación de las fronteras, las etnias quedaran repartidas en varios estados nacionales.

Para los indígenas, las consecuencias de la neoglobalización se expresan, según Stefano Varese, a partir de la declaración del "carácter transnacional, trans-fronterizo y trans-estatal de numerosas etnias indias como un hecho histórico de larga duración que se remonta al reparto territorial colonial y a su ulterior confirmación post-colonial". En varios países de Latinoamérica, un mismo grupo indígena comparte territorios fronterizos contiguos pertenecientes a estados-naciones distintos. La herencia colonial de comunidades locales fragmentadas y desconectadas de su entidad étnica integral es rechazada a través de la búsqueda de estrategias políticas que intentan recuperar su soberanía indígena perdida. Los grupos indígenas se reagrupan, reconstruyendo sus historias y reconfigurando sus proyectos étnico-políticos, en un proceso de relocalización. Frente al efecto mundial contemporáneo de la globalización desde arriba los pueblos indios comienzan a responder con una globalización desde abajo (Cfr. Varese, 1997: 23-32).

El economista Hernando de Soto, fundador del ILD, calificado por The Economist como el segundo think tank más importante del mundo, ha estudiado que en los países andinos la mayor parte de la población sobrevive en el sector de las economías informales y no participa del esquema de la división del trabajo. Esto es causa de una falla en la implementación de modelos económicos de mercado, dado que la mayoría está al margen de los mecanismos del crédito y la inversión.

De Soto incluye entre los países desarrollados a aquellos que pudieron integrar a sus sectores informales a través de un sistema en el cual los convenios y contratos sociales están reflejados en la ley y en la estructuración profunda de su sistema político. Como sostiene el economista peruano, la tendencia a pensar que la "economía de los pobres" solamente consiste en el asistencialismo y no en su participación en las economías de mercado, ha sido el factor fundamental para frenar su inserción en el sistema amplio.

En términos técnicos, esta responsabilidad política se define en el modelo de las "redes de racionalidad", desarrollado desde la base teórica aportada por el economista Julio H. G. Olivera. La propuesta acerca de las "redes de racionalidad" apunta a la tarea de implementar "tecnologías de la decisión" que permitan superar el ensimismamiento al que se exponen las sociedades arrinconadas y, por ello, imposibilitadas de delinear su futuro.

Muhammad Yunus, Premio Nobel de la Paz, Profesor de la Universidad de Bangladesh y Fundador del Banco de los Pobres (Grameen Bank), ha desarrollado un exitoso modelo basado en una "conciencia social de la empresa capitalista", modelo que promueve el entrenamiento en diferentes áreas del desarrollo social a través de un soporte educativo que brinde oportunidades a los más carenciados para apropiarse de algunas claves del mercado. "La pobreza es una enfermedad crónica. No se la puede curar con medidas ad hoc. Puede haber medidas de corto aliento, pero hay que contar con una estrategia de largo plazo cada vez que se da un paso táctico" dice Yunus, para quien la caridad tiene efectos desastrosos.

Des-construyendo los modelos culturales patriarcales y desafiando a las organizaciones económicas internacionales -como el Banco Mundial-, el catedrático doctorado en Vanderbilt University construyó un sistema de microcréditos destinado fundamentalmente a mujeres, que ya ha sido adoptado en varias naciones del planeta. El sistema de microcréditos ideado por Muhammad Yunus beneficia en un 94 \% a las mujeres. Él considera a las mujeres actores privilegiados del desarrollo y critica el sexismo de los sistemas bancarios de varios países, en los que se pregunta a las mujeres si han consultado a sus maridos acerca de la decisión de tomar un préstamo.

Las pautas culturales conspiran contra el género femenino y Yunus opina:

(...) las mujeres que viven en la miseria se adaptan mejor y más rápido que los hombres al proceso de autoasistencia. Asimismo, son más atentas, intentan asegurar el porvenir de sus hijos con más eficacia y demuestran mayor constancia en el trabajo. Cuando es manejado por la mujer, el dinero es mejor utilizado en beneficio de la familia que si el hombre lo maneja.

Si los objetivos del desarrollo apuntan al mejoramiento de las condiciones de vida, a la absorción de la pobreza y a la reducción de las desigualdades, tendremos que compartir la opinión de Yunus, a quien le parece natural comenzar reparando las situaciones anómalas de las mujeres en el mundo.

Como observa Geert Hofstede, la evolución demográfica indica que debieran reducirse las tasas de natalidad en el mundo. Además de las consecuencias económicas, el tamaño de la población es un elemento que puede definir la distancia jerárquica, por cuanto favorece la dependencia de la autoridad. Así, 
en un país muy poblado, los ciudadanos tendrán que aceptar un poder político más distante y menos accesible que los habitantes de una nación pequeña. El control de la natalidad puede desembocar en una feminización de los valores, pues en las culturas femeninas la madre tiene mayor capacidad acerca del número de hijos a concebir y adapta ese número a los recursos disponibles. En los países pobres, la cultura prevaleciente es la masculina, en la que es el padre quien decide el tamaño de la familia.

Finalmente, el crecimiento de la población también está muy relacionado con el colectivismo. Cuando no se debe a la inmigración, ese crecimiento es el resultado de un promedio elevado de hijos por familia. No resulta extraño que en países con alta tasas de natalidad, entre las familias numerosas se inculquen valores colectivistas y no individualistas (1999: 183186).

\section{El rol de los investigadores}

Una imagen ambivalente refleja la tragedia argentina: "País rico y pueblo pobre"... Así recalamos en la urgencia de encarar una Reforma Educativa que coopere en la metamorfosis vital. Esta línea entronca con la Economía de la Educación que pone el acento en la capacitación como capital humano. Así, la formación de distintos tipos de líderes sociales (especialistas, científicos, tecnólogos y humanistas) es la única vía para promover la composición de una masa crítica que asegure la permanencia de la sociedad. Estos objetivos pueden lograrse a través de las técnicas del empowerment desplegadas en el campo de la educación avanzada y de la educación no formal, que promueven el adiestramiento de líderes capaces de modificar las estructuras de sus grupos de pertenencia (Poderti, 2000).

Por otra parte, un país que aspira al desarrollo no puede desentenderse de la responsabilidad de diseñar y brindar perdurabilidad a programas estratégicos de ciencia y tecnología. Se ha comprobado que la ausencia del Estado en estas áreas resulta contraproducente y regresiva desde el punto de vista socioeconómico. El proceso de globalización tecnológica, política, económica y cultural sólo favorece a las grandes potencias industriales y al capital transnacional. La unipolaridad política produce el incremento inusitado de las desigualdades sociales, no solamente entre naciones sino también dentro de cada una de ellas.

La revolución científico-tecnológica del siglo $X X$ ha disparado el crecimiento vertiginoso de la informática y las telecomunicaciones, fenómeno que da origen a la llamada sociedad del conocimiento. Las consecuencias de esta situación son impredecibles, pues sus proyecciones no apuntan precisamente a la concreción de una sociedad solidaria, humanista y más justa. La sociedad del conocimiento se equipara con la sociedad informatizada y el auge de la cibernética coloca a los países desfavorecidos en el centro de un negociado multimillonario con empresas de hardware internacionales que reciclan en las naciones pobres su equipamiento desactualizado. Asimismo, en la llamada sociedad del conocimiento, el saber y la información crecen y se vuelven obsoletos a una velocidad incontenible. El conocimiento se convierte en patrimonio de pocos y por ello constituye una mercancía valiosa, pero sobre todo, se transforma en instrumento de poder e inequidad. La dependencia tecnológica y la mediocridad intelectual son fomentadas por los centros de dominación que pretenden administrar nuestra historia.

Junto al crecimiento de la brecha entre riqueza y pobreza tam- bién crece la diferencia entre inforricos e infopobres, por cuanto los países con baja infraestructura de teléfonos quedan marginados, no sólo de las redes de Internet, sino del seguimiento y la inserción en la economía internacional y del diálogo con los cambiantes procesos socio-culturales. (Ford, 1999: 117).

La evolución sin precedentes del conocimiento está aumentando progresivamente las desigualdades entre quienes poseen y no poseen, reproduciendo así disparidades no sólo entre las diferentes naciones de nuestro planeta sino también dentro de cada una de ellas. Pero esta situación también tiene su contraparte positiva, ya que el auge del conocimiento puede conducir a un estadio de expansión del género humano.

El siglo XXI en Latinoamérica se inicia con grandes innovaciones y también con las secuelas de los cambios dramáticos operados en la centuria anterior. La arrolladora revolución tecno-científica coexiste con las consecuencias de las dictaduras militares y el proceso de globalización se impone con sus fuerzas de competitividad. Pero el hecho de vivir en un país agobiado por una crisis económica y social debería desembocar en una instancia de reflexión que apunte a transformaciones cualitativas.

El desafío para el trazado de políticas técno-científicas es claro: un sistema científico no puede actuar aislado de la realidad social y escasamente vinculado con el sector productivo. En un mundo que induce a competir con bloques de naciones ricas y enormes corporaciones transnacionales, es indudable que las capacidades científicas, técnicas, innovadoras y gerenciales ya no pueden ser confiadas a la simple intuición, sino que deben ser el resultado de un estudio permanente, actualizado, crítico y, sobre todo, transdisciplinario. Como ha expresado Víctor Morles (1998), la especialización es un hecho contradictorio. Ella ha permitido al sector económico alcanzar una mayor eficiencia y productividad. Pero en el campo profesional es indudable que la delimitación de los campos de estudio ha conducido a la creación de lenguajes más específicos y al dominio de contenidos altamente complejos y especializados.

La industria y la técnica son hoy las actividades humanas dominantes. Estas prácticas generaron la aparición de un tipo de profesional experto, un hiperespecialista que posee dominio de un sector muy reducido del conocimiento científico, técnico o artístico. Esta situación deriva en la atomización del conocimiento y en la imposibilidad por parte de los profesionales para comprender problemáticas distintas a las de su interés individual.

Según Basarab Nicolescu, uno de los padres de la "transdisciplina", ese proceso de babelización puede traer como consecuencia que los dirigentes se vuelvan cada vez más incompetentes. Un dirigente individual o colectivo es aquel capaz de tener en cuenta todos los elementos del problema que examina. Así, los desafíos más importantes de nuestra época requieren capacidades amplias. La falta de comunicación entre profesionales de distintas ramas ha guiado la búsqueda de estrategias para comprender mejor el mundo y lograr la unidad de la cultura. Así, la ciencia, la tecnología, el arte y la educación se vinculan entre sí y también con otros sectores de la sociedad (la economía, la política, el medio ambiente, etc.). posibilitando la aprehensión de estrategias válidas para lograr la formación de profesionales distintos

En la era del gran bang disciplinar y de la especialización exagerada es posible concebir una supercomputadora programada con los conocimientos de todas las disciplinas. Pero esa supercomputadora podría saber todo y no entender nada. Quien utilizara dicha máquina sólo tendría acceso instantáneo 
a resultados investigativos heterogéneos y no sería capaz de comprender sus significados ni los lazos de unión entre las diferentes disciplinas.

Así, la transdisciplina se convierte en un novedoso enfoque metodológico de indudable utilidad para el estudio de problemas complejos de carácter social, científico, técnico y pedagógico. La transdisciplinariedad es una "actitud que atraviesa y trasciende" las disciplinas. Como se expresa en la Declaración Transdisciplinaria (Portugal, 1994), esta orientación es resultado de un camino evolutivo dirigido a superar la mirada uni-focalizada en el estudio de problemas humanos complejos. El proceso comienza con la consideración de que dichos asuntos no pueden resolverse adecuadamente con una mirada reduccionista de los mismos, sino que se requieren otras perspectivas.

La transdisciplina, como otros enfoques que superan las visiones funcionalistas y atomizadas de la realidad, enfatiza aspectos que pueden lograr una visión integradora del hombre, la sociedad y la naturaleza. La transdisciplinariedad es valiosa por su énfasis en el rigor, la apertura y la tolerancia. Rigor en la argumentación, tomando en cuenta toda la información disponible como la mejor barrera contra toda posible distorsión. Apertura, que implica aceptación de lo desconocido, lo inesperado y lo impredecible. Y tolerancia, que significa un reconocimiento al derecho a existir que tienen las ideas opuestas a las nuestras.

Por ello, en los países más desarrollados del mundo, los sistemas de investigación científico-tecnológicos están ligados a un vigoroso régimen de educación avanzada cuya función es la capacitación profesional de más alto nivel. Se promueve así el establecimiento de ambientes que incentiven la racionalidad y la crítica pero, sobre todo, la creatividad intelectual científica, técnica o artística. Evidentemente, el instrumento principal que debe estimularse es el cerebro, esa computadora capaz de razonar, criticar y crear, una herramienta tan potente entre los latinoamericanos como lo es entre norteamericanos o europeos (Cfr. Morles, 1997 y 1998).

Porque en nuestro tiempo el crecimiento social y económico no se produce solamente con políticas financieras, fiscalistas o de control social, ni con abrupta privatización y apertura de mercados, sino fundamentalmente a través de un fuerte impulso a la formación de recursos humanos. La aparición de grandes bloques regionales que combinen su caudal científico tecnológico y económico devendrá en la búsqueda de soluciones racionales. Éstas habrán de delinearse a través del trabajo conjunto de políticos, empresarios e investigadores.

De este modo, en torno a la coyuntura ciencia-globalización, se generan interrogantes elementales para el presente y el futuro de Argentina: ¿Puede un país sin un sistema científico adecuado insertarse satisfactoriamente en una sociedad de alta complejidad, mundializada y tecnificada? ¿Puede un país sin recursos humanos capacitados participar medianamente en el concierto económico internacional? ¿Podrá desarrollar la industria, la agricultura, la minería y todas sus potencialidades económicas? ¿Podrá negociar hábilmente con los expertos de las grandes empresas transnacionales o de los organismos financieros mundiales? ¿Estará preparado para entender lo que hay detrás de cada convenio que firma?...

\section{Acorde final}

Los distintos momentos de incertidumbre y cambio en nuestro mundo, representados por términos como globalización, regionalización, nación, implican procesos que hoy vuelven más complejo el panorama de las identidades. Estamos así frente a un cambio paradigmático, lo que implica un giro en la visión epistemológica y cosmológica.

Por un lado se nos plantea que hoy podríamos elegir, deliberadamente, la identidad que más se asoma a nuestra percepción de nosotros mismos: si pertenecemos a una nación, si somos ciudadanos del sistema global, o elegimos ser miembros de un grupo étnico, religioso, o de determinada orientación sexual, etc. Esa cultura globalizada compartida nos hace preguntar quién va a producir los gestos auténticos de nuestra realidad.

Pero indudablemente la mayor parte de nosotros es y puede ser definida como inmigrante, ya que su identidad se explica inmersa en la frontera, término que en su moderna acepción para las ciencias sociales es una zona trans-geográfica y transnacional. Quizás, como expresa Dertouzos, "se aproxima una nueva era de la unificación que despejará el camino hacia la cuarta revolución, la cual, más allá de los artefactos humanos y sus consecuencias, se dirigirá hacia adentro, en busca de la comprensión de nosotros mismos." (1997: 336)

\section{Bibliografía}

- $\quad$ Anderson, B. (1993). Comunidades imaginadas. Reflexiones sobre el origen y la difusión del nacionalismo, México: Fondo de Cultura Económica.

Bazán, A. R. (1992). El Noroeste y la argentina contemporánea, Buenos Aires: Plus Ultra.

(1986). Historia del Noroeste Argentino, Buenos Aires: Plus Ultra.

Bilbao, F. (1987). Obras Completas, Santiago de Chile: Pedro Pablo Figueroa (ed.)

Canal Feijóo, B. (1946). "Lo que persigue nuestro congreso", en PINOA, Boletín N ${ }^{\circ}$, Buenos Aires, 15 de junio.

(1945). Los problemas del pueblo y de la estructura en el norte argentino, Catamarca: Instituto Nacional del Profesorado Secundario de Catamarca.

De Soto, H. (2000). Entrevista realizada por Astrid Pikielny para La Nación, Buenos Aires: Domingo 3 de setiembre de 2000, p. 3.

- Dertouzos, M. (1997). Qué será. Cómo cambiará nuestras vidas el mundo de la informática, Buenos Aires: Planeta: Prólogo de Bill Gates.

Ford, A. (1999). La marca de la bestia. Identificación, desisigualdades e infoentretenimiento en la sociedad contemporánea, Buenos Aires: Norma.

- García Canclini, N. (1996). Consumidores y ciudadanos. Conflictos multiculturales de la globalización, México: Grijalbo.

(1990). Culturas híbridas. Estrategias para entrar y salir de la modernidad, México: Grijalbo.

- Geertz, C. (1987). La interpretación de las culturas, Madrid: Gedisa. Giddens, A. (2000b). La tercera vía y sus críticos, Madrid: Taururs. -(2000a). La tercera vía. La renovación de la socialdemocracia, Buenos Aires: Taurus.

Hobsbawm, E. (1998). Historia del siglo XX, Buenos Aires: Crítica. Hofstede, G. (1999). Culturas y organizaciones. El software mental. La cooperación internacional y su importancia para la supervivencia, Madrid: Alianza.

- Jalif de Bertranou, C. A. (1997). “Idea de América y función utópica del lenguaje en el pensamiento de Francisco Bilbao", en Memorias de JALLA Tucumán 1995, Jornadas Andinas de Literatura Latinoamericana, Tucumán: Proyecto "Tucumán en el contexto 
de los Andes Centromeridionales", Instituto de Historia y Pensamiento Argentinos de la Facultad de Filosofía y Letras de la Universidad Nacional de Tucumán, vol. II.

- Jameson, F. (1984). Postmodernism, or, the Cultural Logic of Late Capitalism, New Left Review, 146: 53-92.

- Montaner, C. A. (2001). Las raíces torcidas de América Latina, Barcelona: Plaza \& Janés.

- Morles, V. (1998). Transdisciplinariedad, especialización, universidad y post-grado: reflexiones para una discusión, documento de las Primeras Jornadas del Proyecto Transdisciplinariedad, UCV, Caracas, 30 de octubre.

-(1997). Universidad, Postgrado y Educación Avanzada. Publicación del Centro de Estudios e Investigaciones sobre Educación Avanzada, UCV, Volumen 2. Caracas. En colaboración con: Jorge Núñez Jover y Neptalí Alvarez.

- Nicolescu, B. (1997). "La transdisciplinariedad busca discípulos" en Le Monde de l'Education, de la Culture et de la Formation, num. 252, pp. 48-49. Traducción al español de Norma Núñez.

- Olivera, J. H. G. (1999). "Racionalidad técnica y racionalidad ética: el tercer debate monetarista", en Revista Enoikos. Aportes Argentinos para una nueva economía, Buenos Aires: Facultad de Ciencias Económicas de la Universidad de Buenos Aires, Año VII, Número 15

-(1997). "Desarrollo económico y progreso económico" en Economía clásica actual, Buenos Aires: Macchi (versión grabada de la conferencia pronunciada en la Academia Nacional de Ciencias Económicas el 17 de junio de 1971);

- Perón, J. D. (1997). Perón en Doctrina. Ayer Hoy y siempre, Buenos Aires: Megalibros.

- Poderti, A. (2000) Interpelaciones. Cultura tecnológica, reingeniería educativa y empoderamiento regional, Salta: Consejo de Investigación.

-(1999). “Martín Miguel de Güemes y el combate de las pasiones", en Historias de Caudillos Argentinos, Buenos Aires: Alfaguara, Taurus, Aguilar, Altea. Tomo coordinado por Jorge Laffor- gue con prólogo de Tulio Halperín Donghi.

---(1990). "Intertextualidad e intratextualidad en las escrituras de Manuel y Francisco Bilbao", en Revista Anales, Gotemburgo: Instituto Iberoamericano de la Universidad de Gotemburgo, $\mathrm{N}^{\circ} 2$.

Primer Congreso Mundial sobre Transdisciplinariedad. (1994).

"Declaración Transdisciplinaria".- Primer Congreso Mundial sobre Transdisciplinariedad: Portugal, noviembre. Traducción al español de $V$. Morles.

Rojas Mix, M. (1986). “Bilbao y el hallazgo de América Latina: unión continental, socialista y libertaria", en Caravelle, Toulouse: IPEALT, Institut Pluridisciplinaire pour les Etudes sur L'Amerique Latine a Toulouse, $\mathrm{N}^{\circ} 46$.

- Scarano, M. (1997). "América desde el Sur. Notas sobre El Evange lio Americano de Francisco Bilbao", en Memorias de JALLA Tucumán 1995, Jornadas Andinas de Literatura Latinoamericana, Tucumán: Proyecto "Tucumán en el contexto de los Andes Centromeridionales", Instituto de Historia y Pensamiento Argentinos de la Facultad de Filosofía y Letras de la Universidad Nacional de Tucumán, vol. II.

- Tenti, M. M. (2001). "La planificación regional" en el Primer Congreso de Planificación Integral del Noroeste Argentino (PINOA), Separata del Undécimo Congreso Nacional y Regional de Historia Argentina, Córdoba, setiembre de 2001, Buenos Aires, Academia Nacional de la Historia.

- Varese, S. no. (1997). "Identidad y destierro: los pueblos indígenas ante la globalización", en Revista de Crítica Literaria Latinoamericana, Lima-Berkeley, № 46,

- Yunus, M. (1999). Hacia un mundo sin pobreza, Santiago de Chile: Andrés Bello. 